\title{
Cuando las personas se vuelven "mercancías": Respuestas jurídicas para luchar a favor de las víctimas y contra las mafias que trafican en el Mediterráneo
}

\author{
(When people become "merchandise": Legal responses to fight in favor of the \\ victims and against the mafias that traffic in the Mediterranean Sea)
}

\author{
OÑATI SOCIO-LEGAL SERIES, VOLUME 10, ISSUE 4 (2020), 834-849: INVESTIGATIONS - \\ INVESTIGACIONES - IKERLANAK \\ DOI LINK: HTTPS://DOI.ORG/10.35295/OSLS.IISL/0000-0000-0000-1134 \\ RECEIVED 27 OCTOBER 2019, ACCEPTED 14 FEBRUARY 2020
}

\section{Claudia JimÉnez CORTÉS* iD}

\section{Resumen}

Son miles las personas que se juegan la vida por cruzar el Mediterráneo hacia un futuro incierto pero prometedor. En el trayecto -que dura años- pasan a estar a merced de los grupos organizados para quienes son mera "mercancía" de la cual pueden obtener un beneficio... o dos: el que paga la persona o sus familiares por llegar al viejo continente y su explotación por el camino. Esta cosificación hace que la delgada línea que separa el tráfico del delito de trata de seres humanos se difumine cuando no desaparezca. Ante esta realidad, el artículo propone un cambio de enfoque respecto al hasta ahora seguido por las autoridades. Con ello, quizá se consiga luchar de manera más eficiente contra

\footnotetext{
El presente trabajo se enmarca en dos proyectos de investigación; el primero es CIMCETT (La Cooperación internacional como medio imprescindible para combatir el tráfico y la trata de personas: el papel de la UE y otros organismos internacionales), ref. DER2016-78990-P, financiado por el Ministerio de Economía y Competitividad del Gobierno de España. El segundo es 2017-RICIP-00010 (La Comunitat Internacional davant la crisi dels migrants "atrapats" a Líbia).

* Licenciada en Derecho por la UAB en 1988, cuenta con un máster sobre International Human Rights Law cursado al Human Rights Centre de la Universidad de Essex (Reino Unido) en 1990 y un máster en Estudios Europeos por el Instituto de Estudios Europeos de la UAB, 1993. Doctora cum laude por unanimidad en Derecho por la UAB, desde 1997 es profesora Titular de Universidad, especializada en Derecho Internacional Público. Además de los grados de Derecho y de Criminología, imparte docencia en diversos másteres y cursos de posgrado. En cuanto a su trayectoria investigadora, en su etapa más reciente, ha centrado los estudios en los derechos humanos, tanto desde la perspectiva de los derechos como de la acción penal. Esto la ha llevado, a nivel individual, a una consolidación como experta en temas de derecho penal internacional y a nivel colectivo en la participación en los proyectos del equipo sobre temáticas relacionadas con el espacio de Libertad, seguridad y justicia de la UE. Actualmente es la investigadora principal del grupo de investigación financiado por el Ministerio de Economía y competitividad sobre la trata y el tráfico de personas, CIMCETT (La cooperación internacional como medio imprescindible para combatir el tráfico y la trata de personas: el papel de la UE y otros organismos internacionales; http://www.cimcett.es/es/) Datos de contacto: Universidad Autónoma de Barcelona, Campus Universitario, c/ Vall Moronta S/N - 08193 Bellaterra, Cerdanyola del Vallès, Barcelona, España. Dirección de email: claudia.jimenez@uab.cat
} 
esta lacra y en todo caso, al menos se aseguraría un trato más digno y humano a personas que han sufrido en sus carnes el escarnio de no ser consideradas ni tratadas como lo que son, seres humanos.

\section{Palabras clave}

Víctima; delincuencia organizada; contrabando de personas; trata; Mediterráneo

\section{Abstract}

Thousands of people risk their lives to cross the Mediterranean Sea towards an uncertain but promising future. In their journey, they are at the mercy of the organized groups who consider them no more than merchandise from which they can obtain a benefit... or two: one from the person or their relatives for reaching the old continent and one from their exploitation. This "use" of them makes the thin line that separates smuggling from the crime of trafficking in human beings blur if not disappear. Given this reality, the article proposes to focus the persecution on the mafias that have made a profit with their exploitation. With this, perhaps it is possible to fight in a more efficient way and in any case, at least a more dignified and humane treatment would be ensured to people who have suffered the scorn of not being considered or treated as what they are, human beings.

\section{Key words}

Victim; organized crime; people smuggling; trafficking on human beings; Mediterranean Sea 


\section{Table of contents}

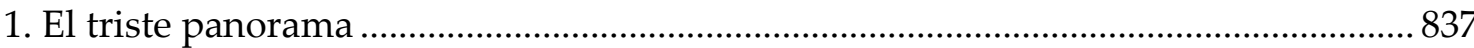

2. Los posibles marcos legales aplicables a los inmigrantes "víctimas" de las mafias. 838

3. La imposible distinción entre trata y tráfico cuando las mafias entran en juego...... 839

4. La "cosificación" de las víctimas de tráfico/trata: un atentado a su dignidad que debe ser combatida

5. El contraste de esta realidad con la actuación de Europa y sus gobiernos

6. La necesidad de un cambio de paradigma: luchar contra las mafias

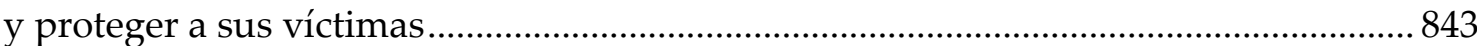

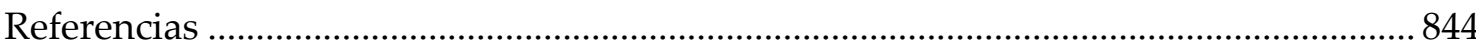

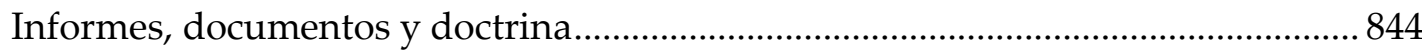

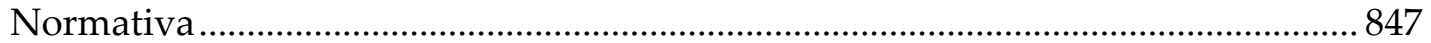

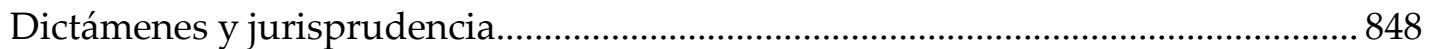




\section{El triste panorama}

Mucho se ha hablado y escrito sobre la crisis humanitaria que en los últimos años se está viviendo en la ruta central del Mediterráneo ${ }^{1}$ a consecuencia de los miles de personas que se juegan la vida por un futuro incierto. Pero su llegada a la tierra prometida no está siendo ni prometida, ni muchas veces siquiera llegada, pues ya se cuentan por miles las víctimas de las mafias que se quedan por el camino, muchas de ellas para siempre. Según el Missing Migrants Project de la Organización Internacional de Migraciones (OIM), las personas fallecidas o desaparecidas en el mar cuando estaban a las puertas de Europa en el 2016 alcanzaron la terrible cifra de casi 4.600, mientras que en el 2017 fueron $2.800{ }^{2}$ Y, aunque en números absolutos, desde el 2018 las muertes han disminuido, porcentualmente, en cambio, las cifras han aumentado. Si en el 2016 las víctimas mortales eran aproximadamente una de cada 45 personas que intentaban llegar a las costas europeas y en el 2017 una de cada 41, según el secretario General de Naciones Unidas a lo largo del 2018 fueron una de cada 14 y en el 2019 la media es de una persona fallecida o desaparecida por cada seis que lo intentan. ${ }^{3}$

A pesar de estas escalofriantes cifras y las terribles vicisitudes que la mayoría de ellas han de superar durante los meses e incluso años que dura el trayecto hacia "El Dorado", lo cierto es que las personas que aspiran a llegar a la "tierra prometida" no cesa. En el 2018 se calcula que fueron casi 40.000 y a septiembre de 2019 ya va por 20.000 (ACNUR 2019a, OIM 2019). Por lo demás, que su llegada a Europa esté disminuyendo se debe en gran medida a que su periplo ahora se ve frenado en los hub de Libia, Turquía o Marruecos a cambio de una cuantiosa inversión en la externalización de las fronteras por parte de los países del viejo continente, no porque haya descendido el número de personas que marcha de su tierra natal en busca de una vida mejor. Prueba de ello es que en el caso de Libia -eje de la ruta del Mediterráneo central-, el último matrix de la OIM de marzo-mayo 2019 ha identificado al menos 641.398 migrantes de 39 nacionalidades distintas atrapados en aquel fallido país (OIM 2019).

De éstos, a pesar de las nuevas dificultades a las que han de hacer frente, según las últimas estadísticas, un 60\% (OIM 2019) de los que finalmente son subidos a precarias embarcaciones para cruzar el Mediterráneo acaba llegando a "lugar seguro" 4 , en donde,

\footnotetext{
${ }^{1}$ La Organización Internacional de Migraciones (OIM) ha divido el Mediterráneo en tres zonas según las rutas de las redes: la zona este, la central y la del oeste. El presente trabajo limita su estudio a la ruta central que desde el 2013 responde fundamentalmente al tráfico marítimo de Libia a Italia (OIM 2020).

${ }^{2}$ Las cifras exactas de personas fallecidas/desaparecidas en el mar que ofrece la web del proyecto de la OIM son de 4.581 en el 2016 (sobre 181.437 llegadas en total) y 2.853 en el 2017 (sobre 122.070 llegadas en total). (OIM s.f.).

${ }^{3}$ Informe del Secretario General de Naciones Unidas al Consejo de Seguridad en aplicación de la resolución 2437 (2018), documento S/2019/711 (Naciones Unidas 2019). Los datos deben contrastarse, sin embargo, con el cruce combinado de informes de ACNUR 2019a y OIM 2019. Según dichas cifras, en el año 2018, 15.235 personas fueron reenviadas a Libia por los guardacostas de ese Estado, 23.064 consiguieron llegar a un puerto seguro europeo y 1.314 fallecieron, lo que supone un 3,3\% sobre el total. Por su parte, hasta septiembre de 2019, 7.042 fueron retornadas por los guardacostas libios, 12.343 llegaron a Europa y 692 fallecieron o desaparecieron, lo que supone un $3,4 \%$.

${ }^{4}$ Denominación utilizada en el acuerdo SAR de Salvamento marítimo para dar por terminada la operación de rescate; ver Anexo 1.3-2 del Convenio Internacional sobre Búsqueda y Salvamento Marítimos (1979, enmendado en 2004). En el presente artículo, por razones obvias y en línea con lo manifestado unánimemente por organismos oficiales, no se considera Libia -y por ende las operaciones de "rescate" de los guardacostas libios como una actividad que culmina en puerto seguro. En este sentido, véase, por
} 
tras lo que debería ser la preceptiva identificación ${ }^{5}$ se les trasladada a centros -en el caso de Italia, centros de acogida (CDA), identificación y expulsión (CIE) o acogida para solicitantes de refugiados (CARA)-, en donde muchos permanecen hasta que se decida qué hacer con cada uno de ellos. ${ }^{6}$

Tanto en el tortuoso viaje como en larga espera, su vida o destino deja de pertenecerles. En la marcha porque su vida está a merced de las mafias que controlan los corredores a Europa: según el informe de Frontex (2019) un 84\% de los migrantes entrevistados "afirmó haber usado los servicios de las redes de contrabando para entrar en la UE", porcentaje que en el caso específico de la ruta del Mediterráneo central según el informe de 2017 ascendió hasta el 96\% (Frontex 2017, p. 8, y 2019, p. 28). Y en la llegada porque su destino depende de las autoridades nacionales del estado de acogida, que deciden quién se queda, quién sigue en el "limbo" y quien, tras años de vicisitudes, ha de retornar "a la casilla de salida".

\section{Los posibles marcos legales aplicables a los inmigrantes "víctimas" de las mafias}

Para determinar quién finalmente consigue el objetivo perseguido, quién será trasladado a otro Estado y quién retornado a su país de origen, la autoridad nacional, por imperativo legal, debe analizar las circunstancias personales de cada inmigrante rescatado del mar y en función de ello valorar cuál de los posibles marcos normativos nacionales e internacionales existentes es aplicable. Las opciones sobre el papel parecen ser muy claras: o se reúnen los requisitos que exige la Convención de 1951 para obtener el estatuto de refugiado (Artículo 1 de la Convención sobre el Estatuto de los Refugiados de 1951 y la enmienda del Protocolo, de 1967); o se es víctima de trata y por tanto puede quedar amparada por la normativa europea que regula esta materia ${ }^{7} \mathrm{o}$, simplemente, es un inmigrante irregular que acudió a terceros para que le ayudasen a entrar ilegalmente al país y en consecuencia queda sometido a las normas en materia de inmigración, con

ejemplo, el informe del Secretario General sobre Libia (Naciones Unidas 2019, párr. 53), o el de la Fiscal de la Corte Penal Internacional ante el Consejo de Seguridad (CPI 2019, párr. 30-38).

${ }^{5}$ El informe de 2017 basado en la visita de urgencia a Italia describió esta identificación como la comprobación, registro, fotografía y toma de huellas dactilares de los inmigrantes, pero sin entrar en cuestiones sobre su situación particular, posible estatus o condición que es fundamental para detectar víctimas de trata (GRETA 2017, p. 11, pto. 39). Y aunque en el nuevo informe de 2019 se señala que ha habido mejoras, la identificación sigue dejando mucho que desear, especialmente porque se ha diseñado un mecanismo de identificación, pero no se aplica (GRETA 2018, párrafos 142 y ss.).

${ }^{6}$ Un relato periodístico sobre el duro periplo de los llegados a las costas italianas y luego su incierta estancia en los centros de acogida fue narrado por los periodistas Alex Perry y Connie Agius (2015) en su artículo $A$ Carpet of people in the sea, publicado en Newsweek.

${ }^{7}$ La definición más universal de "víctima de trata" es la prevista en el artículo 3 a) del Protocolo de Palermo de 2000: "[E]s víctima de trata toda persona que haya sufrido el delito de "la captación, el transporte, el traslado, la acogida o la recepción de personas, recurriendo a la amenaza o al uso de la fuerza u otras formas de coacción, al rapto, al fraude, al engaño, al abuso de poder o de una situación de vulnerabilidad o a la concesión o recepción de pagos o beneficios para obtener el consentimiento de una persona que tenga autoridad sobre otra, con fines de explotación (...)" (Protocolo para prevenir, reprimir y sancionar la trata de personas, especialmente mujeres y niños, que complementa la Convención de las Naciones Unidas contra la Delincuencia Organizada Transnacional, p. 319). En cuanto a la normativa europea, las principales normas son el Convenio del Consejo de Europa sobre la Lucha contra la trata de seres humanos firmado en Varsovia el 16 de abril de 2005 y la Directiva 2011/36/UE del Parlamento Europeo y del Consejo, de 5 de abril de 2011, relativa a la prevención y lucha contra la trata de seres humanos y a la protección de las víctimas. 
las correspondientes sanciones administrativas -que no penales $^{8}$ - que prevea ese estado, incluida la expulsión.

Así entendido, existe una clara diferencia entre las dos primeras situaciones -en donde el bien jurídico a proteger es la dignidad de esos inmigrantes considerados jurídicamente "víctimas" y que por tanto cuentan con el reconocimiento de derechos y estándares de protección"- y la tercera: el inmigrante irregular que "acude" a las mafias para llegar a Europa. En este último supuesto, la visión comúnmente aceptada y aplicada sin fisuras por la UE es que, al tratarse de una situación de tráfico ilícito de personas, el bien jurídico afectado es la potestad del Estado de controlar los flujos migratorios. Por tanto, a estas personas, sin llegar a considerarlas "delincuentes", tampoco cabe considerarlas víctimas dada su participación activa mediante el consentimiento. A partir de aquí, la UE ha optado por tratar a este inmigrante como un "actor" en el proceso, prescindiendo así en sus dos principales instrumentos de cualquier mención a posibles medidas dirigidas a su protección y asistencia (Decisión marco 2002/946/JAI, pp. 1-3, y Directiva 2002/90/CE, pp. 17-18.), en claro contraste con el Protocolo de Nueva York (Protocolo contra el Tráfico Ilícito de Migrantes por Tierra, Mar y Aire, 2000, p. 480) que concibe al inmigrante irregular como "objeto" del delito de tráfico llevado a cabo por la delincuencia organizada y en consecuencia prevé cierto marco de protección y asistencia. ${ }^{10}$ La perspectiva europea señalada, lejos de revisarse se vio reafirmada en el Plan de Acción de 2015-2020 que por un lado insiste en su participación (Plan de Acción de la UE contra el Tráfico de Migrantes 2015-2020, p. 3), y por otro limita la posible asistencia a una breve referencia potencial y sólo dirigida a "migrantes vulnerables" (ibid., punto II.3).

\section{La imposible distinción entre trata y tráfico cuando las mafias entran en juego}

La distinción entre asilado, víctima de trata o mero inmigrante irregular, que sobre el papel parece muy clara y que entraña consecuencias vitales para las personas llegadas a las costas italianas, a la hora de trasladarla a su dramática realidad se vuelve difusa, especialmente cuando se debe valorar si se está en presencia de una mera situación de tráfico o si se cabe reconocer a ese inmigrante irregular también la condición de víctima de trata de seres humanos, lo cual le permitiría acceder a la protección subsidiaria. ${ }^{11}$ Ello se debe a que los elementos comunes a ambas conductas delictivas persisten (movimiento de personas y obtención de beneficio) y en cambio los estrictamente característicos de cada una de las conductas (consentimiento y transnacionalidad en el

\footnotetext{
${ }^{8}$ Como bien señala Guardiola Lago (2016, p. 556), debe diferenciarse la inmigración irregular que efectúan quienes llegan a las costas europeas y que es una conducta atípica, del tráfico ilícito de migrantes en donde hay la intervención de un tercero que es lo que y a quien se sanciona penalmente.

9 Sobre la condición de víctima en el delito de trata y su protección, véase, por todos, Jordana Santiago 2015, pp.65 y ss.

${ }^{10}$ Artículo 16 y también las referencias en los artículos 18.7 y 19 en relación a los principios de non-refoulement y no discriminación.

${ }^{11}$ En el caso de Italia ello podría implicar acceder a un permiso de residencia en aplicación del artículo 18.3 incorporado por el Decreto Legislativo 24/2004 al Decreto Legislativo no . 286, de 26 de julio de 1998, conocido como "ley de inmigración consolidada".
} 
tráfico frente a captación indebida con finalidad de explotación en la trata) no están tan claros. $^{12}$

Así, respecto a la transnacionalidad, sin ser éste un requisito de la trata, nada impide que se pueda dar y de hecho así sucede en todos los potenciales casos de trata de inmigrantes llegados a Europa por la ruta central mediterránea. En cuanto al "consentimiento", que como se ha visto es clave en la lógica de la UE para no reconocer al inmigrante objeto de tráfico la condición de víctima, éste en la práctica puede en muchas ocasiones ser también enmarcable en la definición de "captación indebida" de la definición de trata, que incluye no sólo la coacción sino también el engaño, el fraude e incluso el abuso de poder o de una situación de vulnerabilidad de la víctima. De hecho, el abuso de poder o la situación de vulnerabilidad son una constante entre los inmigrantes que caen o acuden a las redes de la ruta central, por lo que resulta difícil mantener que su libertad de decisión en ningún momento se ha visto alterada (García Arán 2006, pp. 16-17). Por otro lado, en términos de trata, es aceptado que en la captación cabe la posibilidad de un consentimiento inicial. Lo que sucede es que perderá su relevancia por la coacción, el engaño o el abuso, y en caso de menores ni eso (Villacampa 2011, p. 45). En definitiva, para determinar si existe el consentimiento típico del tráfico que lo diferencia de la trata se debe evaluar si el emigrante mantiene el dominio del hecho del traslado en todo momento. Y eso, en los relatos de las personas que caen en manos de las redes organizadas, no parece ser así (OIM 2017).

Por último, el otro eje sobre el que podría girar la determinación de una $u$ otra calificación es la finalidad de explotación que conlleva la trata. Al respecto y como premisa previa, como señala Villacampa (2011), debe tenerse claro que el delito de trata "no se focaliza específicamente en la fase de explotación (...) sino que se circunscribe al tránsito de una situación de no sometimiento a la de sometimiento". En otras palabras, lo que es punible en tanto que trata es el mecanismo mediante el cual se consigue la sumisión, de aquí que se hable muchas veces de un delito en cadena que no requiere necesariamente la consumación de la explotación para apreciarse. ${ }^{13}$ Es esta característica la que permite afirmar que lo más relevante no es la explotación en sí sino el proceso que tiene tal finalidad y que en el fondo implica "transformar" a la persona en cosa. Tal reducción del ser humano, en el ámbito penal y criminológico se conoce como la "cosificación", esto es, la desconsideración hacia su condición humana para ver y tratar a una persona como simple "mercancía", lo cual sin duda es un atentado contra la dignidad, el bien jurídico protegido en el delito de trata. Por ello, aunque a primera vista resulte hasta paradójico, es precisamente aquí en donde más se difumina la distinción entre trata y tráfico, al menos cuando ambas son controladas por redes delictivas organizadas y sus víctimas son migrantes con una alta vulnerabilidad económica, social y/o psicológica (UNODC 2011).

\footnotetext{
${ }^{12}$ Los elementos comunes y diferenciales aquí señalados se han extraído de UNODC 2007, pág. xiv. Otro posible listado de los elementos básicos de la trata se encuentra en el Informe explicativo del Convenio del Consejo de Europa sobre la lucha contra la trata de 2005 citado por el Tribunal Europeo de Derechos Humanos (TEDH) de acción, medios y finalidad, aunque en el fondo señala las mismas semejanzas entre trata y tráfico; ver Chowdury y otros c Grecia, n⿳o. 21884/15, párr.43.

${ }^{13}$ La consumación de la explotación normalmente implica otro delito como explotación sexual, trabajo forzoso, esclavitud, etc., abriendo la puerta a un posible concurso medial de delitos. Así lo ha interpretado el Tribunal Supremo en España: STS 807/2016 y STS 538/2016.
} 


\section{La "cosificación" de las víctimas de tráfico/trata: un atentado a su dignidad que debe ser combatida}

El modus operandi de las redes de tráfico/trata no deja lugar a dudas de la "cosificación" de los migrantes vulnerables con los que "contrabandean". Ello ha sido reconocido por los tribunales italianos (Decisión del Tribunal de primera instancia de Palermo 3714/2016 R.G.N.R.) y la propia Unión Europea, que, en el Plan de Acción ya citado, señala que "los traficantes tratan a los migrantes como mercancías, igual que las drogas y las armas con las que trafican en las mismas rutas" (Plan de Acción 2015-2020, p. 2).

De aquí que, como se ha señalado en reiteradas ocasiones, muchas situaciones que inicialmente empiezan como un caso de tráfico ilícito de migrantes o que se pueden calificar como tales acaban desembocando en un delito de trata (entre otros, Nyczak 2017, p. 266). La coincidencia del sujeto activo de ambos delitos (las mafias) y la vulnerabilidad de los migrantes que utilizan la ruta central (mayoritariamente nigerianos, eritreos, gambianos, marfileños y sudaneses) (ACNUR 2017, p. 7) hace que, en función de las circunstancias, la mayor parte de las personas con las que trafican sean o se acaben convirtiendo, al menos durante el trayecto, en víctimas de trata y/o sometida a tratos vejatorios, calificables de inhumanos cuando no tortura. Así lo ha constatado la OIM (2017) en un muestreo de 2.769 entrevistas celebradas en el 2017. En ellas, un 79\% contestó afirmativamente a al menos uno de los cuatro indicadores de trata de personas, y un $50 \%$, a dos de ellos (OIM 2017).

Esta relación entre las dos conductas delictivas que puede llevar a situaciones de superposición, como señala García Arán (2006), no es coyuntural, pues en ambas las redes delictivas que controlan las rutas de contrabando ven un "negocio que tiene como objeto a la persona que, pese a concurrir su voluntad (a veces), se convierte en mercancía... e incluso es tratado como una cosa" (García Arán 2006, p. 18). Es esta cosificación que sufre el inmigrante que cae o se pone en manos de la delincuencia organizada la que sin duda los convierte a todos ellos en víctimas, haciendo irrelevante el posible consentimiento inicial y, en esa medida, debe protegérseles y garantizárseles sus derechos fundamentales en tanto que seres humanos.

\section{El contraste de esta realidad con la actuación de Europa y sus gobiernos}

No es éste, sin embargo, el enfoque adoptado ni por la Unión Europea ni por sus estados miembros. Las manifestaciones y soluciones articuladas desde las instituciones y los gobiernos en relación a la "crisis del Mediterráneo" -como la firma de acuerdos con países de origen o tránsito, destrucción de las embarcaciones, formación de guardacostas en el caso libio o mejoras en las operaciones de retorno- dejan muy claro que para los europeos el problema es básicamente de inmigración irregular, lo que les permite no reconocer la condición de víctima a aquellos que han sido objeto de contrabando por las redes criminales. Es más, dado el reconocimiento de la situación de cosificación de los migrantes, el Plan de Acción de 2015-2020 por un lado recuerda que las normas y estrategias para combatir el tráfico y la trata son distintas (Plan de Acción 2015-2020, p. 3) y por otro hace un verdadero esfuerzo por acentuar las diferencias entre ambos delitos, insistiendo en que la distinción radica en la voluntariedad y el pago a los traficantes por sus servicios en el caso de tráfico, añadiendo incluso que la trata exige 
una explotación "extrema", calificativo que no consta en ninguna de las normativas internacionales vigentes (Plan de Acción 2015-2020, p. 3).

Por si ello no fuera suficiente, los hechos también corroboran este enfoque. Sin entrar en detalles, informes tanto de organismos intergubernamentales como no gubernamentales dan a entender que, al igual que en temas de retorno, ${ }^{14}$ en los análisis individualizados de las circunstancias de cada persona que alcanza las costas para valorar su grado de victimización y consecuente necesidad de protección ${ }^{15}$ hay cuando menos grandes deficiencias, tanto en la tramitación de asilo como especialmente en la detección de víctimas de trata, con lo que la gran mayoría de recién llegados acaban siendo considerados simples inmigrantes irregulares. ${ }^{16}$ El informe de GRETA de 2019, en línea con lo ya señalado en su anterior informe de 2016 sobre la situación en Italia no deja lugar a dudas. ${ }^{17}$ Por lo demás, las estadísticas corroboran esa apabulladora opción hacia el trato de inmigrante irregular sin más, a pesar muchas veces de existir claros indicios de su condición de víctima de trata. ${ }^{18}$ De hecho, según consta en el perfil de Italia de la web de UNODC en el 2016 (último año recogido) sólo 679 personas fueron detectadas como víctimas de trata, incluyendo tanto las europeas como no europeas (UNODC 2018, p. 34), cuando en ese mismo año, según Frontex (2017), sólo entre nacionales nigerianos entraron por la ruta central más de 37.000 (Frontex 2017, p. 19). Y la situación en estos últimos tiempos, por lo que se desprende del ya mencionado informe GRETA (2019) no parece haber cambiado. En él, además de manifestar su preocupación por la opción de formar a guardacostas libios para los rescates y que exista una verdadera aproximación centrada en la víctima de trata y la protección de los derechos fundamentales en la operación Themis, se recomienda a Italia que mejore la capacitación de las autoridades que deberían detectar situaciones de trata entre las personas que llegan a sus fronteras, que tome medidas para garantizar una mejor y más temprana identificación o que asegure un acceso rápido y efectivo a la asistencia y protección de víctimas de trata entre los migrantes y refugiados procedentes del mar. De hecho le recomienda incluso que provea información a los extranjeros sobre sus derechos, asistencia o asesoramiento legal y que lo haga en una lengua que puedan entender (GRETA 2018, párr. 140 y 141).

De lo dicho no cabe duda de que existe una verdadera voluntad política de no abordar esta problemática desde una perspectiva de trata o delincuencia organizada sino estrictamente migratoria y dentro de ésta, centrada básicamente en cómo evitar más entradas irregulares, prescindiendo tanto de los autores del delito como de la situación

\footnotetext{
${ }^{14}$ Véase la decisión del TEDH en el caso Khlaifia y otros c. Italia (2016). Esta decisión fue revisada y en parte matizada por la posterior sentencia de la Gran Sala, de 15 de diciembre de 2016, tras ser referida a ella por el Gobierno de Italia.

${ }^{15}$ Con ello se hace referencia no sólo a la normativa internacional vigente en materia de asilo y trata sino también de derechos humanos en general. Así lo ha señalado repetidamente el Comité de Derechos Humanos. Véase, por ejemplo, el dictamen de 23 de julio de 2015, Osayi Omo-Amenaghawon c. Dinamarca, en sus puntos 7.2 y 7.5 .

${ }^{16}$ A nivel intergubernamental, véase el informe de GRETA sobre Italia (GRETA 2017) y, a nivel no gubernamental, véase, entre otros muchos, International Rescue Committee et al. 2017, en relación a Grecia, o la primera parte del informe del European Council on Refugees and Exiles (ECRE), 2016.

17 GRETA 2016, por ejemplo, las recomendaciones de los puntos 72-73 y los puntos 28, 31, 40, 45 o 61., y GRETA 2018, por ejemplo, párrafos 141, 158 o 266.

${ }^{18}$ Según consta en el informe GRETA (2017) la representación de la OIM en Italia consideraba que el 70\% de mujeres y niños no acompañados que llegaban de Nigeria mostraban indicios de haber sido víctimas de trata. (GRETA 2017, punto 34; véase, en un sentido similar, el punto 44).
} 
personal de aquellos que en el trayecto consiguieron no dejarse la vida, pero sí su integridad. ${ }^{19}$

\section{La necesidad de un cambio de paradigma: luchar contra las mafias y proteger a sus víctimas}

La obcecación de la Unión Europea y sus estados miembros por restringir la entrada de migrantes irregulares, desde luego, no obedece a una real e inasumible avalancha y menos aún si con ello se refieren a las personas que entran por mar. ${ }^{20}$ Incluso en el período más álgido de la "crisis migratoria", entre 2013 y 2016, el total absoluto de personas detectadas como migrantes irregulares por cualquier ruta en todo el territorio de la Unión fue de 2.723.846 (Frontex 2017, tabla 1, p. 47). Puesto en perspectiva, eran casi un millón menos que los refugiados acogidos en 2018 por un solo estado: Turquía (3.700.000) (ACNUR 2019b), con el agravante que en el caso de la Unión ello representó tan sólo el $0,5 \%$ de su población. De éstos, los procedentes de la ruta central fueron 566.518, el equivalente a la población de Málaga.

La errónea percepción de "invasión" retroalimentada desde y hacia la opinión pública, junto a la insistencia de que se trata de personas que contrataron los servicios de las mafias para entrar ilegalmente y no de víctimas, genera una imagen de ellos que los convierte en sujetos "no deseados", abocándolos a una nueva situación de vulnerabilidad y desprotección, ahora en el territorio europeo, que sólo sirve para agravar aún más la situación. ${ }^{21}$ Por ello, tanto razones humanitarias como de eficacia (frenar las oleadas de botes hacinados surcando el Mediterráneo), exigen un cambio de paradigma: centrar la lucha en el sujeto activo y no en su víctima.

Su materialización pasaría, entre otros, porque tanto la normativa como las estrategias o planes de acción de la Unión Europea y sus estados miembros para luchar contra el contrabando de personas (en régimen de tráfico o trata) se enfocasen y aplicasen en una línea similar a la de los Protocolos del 2000 de la Convención de Naciones Unidas contra la Delincuencia Organizada Transnacional (2004), esto es, en tanto que marcos legales de ámbitos sectoriales específicos y no contrapuestos, que complementan la norma principal cuyo objeto es la lucha contra estas estructuras criminales (ver Art. 1.1. de ambos protocolos). En el caso de la UNODC eso permite, en una misma situación, combinar las herramientas normativas de ambos Protocolos y de éstos con las de la Convención, como por ejemplo las relativas al blanqueo de dinero, las dirigidas contra la corrupción, el decomiso e incautación o incluso la cooperación internacional -incluida la penal- cuando existe una confianza mutua suficiente.

\footnotetext{
${ }^{19}$ En este sentido, cabe destacar lo manifestado en el informe Frontex 2019, según el cual en las fronteras marítimas ha habido un "desproporcional decrecimiento" de detecciones de traficantes más allá de la disminución general lo que le lleva a sugerir que las mafias han conseguido un mejor funcionamiento pudiendo quedar fuera del alcance de la ley de los Estados, aunque en nuestra opinión también pudiera ser que haya decrecido la presión o el interés por su persecución (Frontex 2019, p. 24).

${ }^{20}$ La OIM calcula que sólo un $10 \%$ de los migrantes irregulares entran a Europa por mar; véase Cano Linares 2016, p. 286.

${ }^{21}$ Véase, en esta línea, por ejemplo, Verdú 2017 o el auge de los partidos xenófobos como el Frente Nacional francés; la Liga italiana; Fidesz, de Hungría; AfD, de Alemania; o Vox, de España, que basan parte de su campaña en un discurso contra la inmigración.
} 
Junto a ello y en línea con lo señalado por Pérez Cepeda (2004, p. 29), se debería también reenfocar el delito de tráfico ilícito y centrarlo más en el comportamiento del autor del delito y no en el consentimiento de la persona objeto del mismo. Ello permitiría que en casos de cosificación no calificables de trata la persona pudiese igualmente ser considerada víctima de contrabando, con la consiguiente protección. Un replanteamiento en este sentido conseguiría dos objetivos. Por un lado, incluir en el bien jurídico protegiendo la dignidad de los inmigrantes (derecho a no ser cosificados; Guardiola Lago 2016, p. 591) y por otro, abrir la puerta a la posibilidad de contar con estas personas para combatir la criminalidad, algo que, tal y como ponen de manifiesto algunas decisiones judiciales españolas e italianas, resulta clave para el éxito de la condena penal de los miembros de las redes criminales. ${ }^{22}$

Por último, frente a la alternatividad que las autoridades administrativas parecen venir aplicando a las situaciones de trata y tráfico -debido en gran parte a la relevancia dada al consentimiento presumido de iure en casos de tráfico- debería optarse por una visión que admita el concurso de ambos, como de hecho se empieza a ver en cierta jurisprudencia de estos mismos países. ${ }^{23}$

Las decisiones judiciales citadas en este trabajo parecen indicar que parte de la judicatura podría estar por la labor. Por el respeto de los valores europeos (consagrados en el artículo 2 del TUE) sería deseable que el resto de autoridades también lo estuviesen.

\section{Referencias}

Informes, documentos y doctrina

ACNUR, 2017. Desperate journeys [en línea]. Febrero. Disponible en: http://www.unhcr.org/58b449f54.pdf [Con acceso el 17 de marzo de 2020].

ACNUR, 2019a. Libya: activities at disembarkation, September 2019 [en línea]. Disponible en: https://data2.unhcr.org/en/documents/download/71743 [Con acceso el 17 de marzo de 2020].

ACNUR, 2019b. Tendencias globales. Desplazamiento forzado en 2018 [en línea]. Disponible en: https://www.acnur.org/5d09c37c4.pdf [Con acceso el 17 de marzo de 2020].

Cano Linares, A., 2016. Lucha contra el tráfico ilícito de migrantes versus estatuto del refugiado: evolución de la actuación de la Unión Europea en la cuenca del Mediterráneo. Ordine internazionale e diritti umani [en línea], vol. 2016, pp. 282-302. Disponible en: https://www.academia.edu/31816539 [Con acceso el 17 de marzo de 2020].

Comisión Europea, Migración y Asuntos de Interior, sin fecha. Irregular Migration $\mathcal{E}$ Return [en línea]. Disponible en: https://ec.europa.eu/home-affairs/what-we-

\footnotetext{
${ }^{22}$ En el caso de Italia, confirmación de la orden de detención preventiva emitida por el Tribunal de primera instancia de Calabria, ref. 3714/2016 R.G.N.R, y en el de España, STS 824/2016.

${ }^{23}$ Véase, por ejemplo, en el caso de Italia la orden de detención preventiva del Tribunal de Palermo, ref. 615/2017 DDA R.G.N.R., y en el de España, la STS 807/2016 o la STS 77/2019 e incluso, más rotundamente hablando de "cosificación" y por tanto calificando los hechos punibles como trata y no como tráfico, la reciente STS 396/2019.
} 
do/policies/irregular-migration-return-policy en [Con acceso el 17 de marzo de 2020].

Corte Penal Internacional, 2019. Seventeenth Report of The Prosecutor of The International Criminal Court to the United Nations Security Council Pursuant to UNSCR 1970 (2011) [en línea]. 8 de mayo. Disponible en: https://www.icccpi.int/itemsDocuments/190508-rep-otp-UNSC-libya-ENG.pdf [Con acceso el 17 de marzo de 2020].

European Council on Refugees and Exiles, 2016. Admissibility, responsibility and safety in European asylum procedures [en línea]. Septiembre. Disponible en:

https://www.ecre.org/wp-content/uploads/2016/09/ECRE-AIDA-Admissibilityresponsibility-and-safety-in-European-asylum-procedures.pdf [Con acceso el 17 de marzo de 2020].

Frontex, 2017. Risk Analysis for 2017 [en línea]. Varsovia: Frontex Risk Analysis Unit, Febrero. Disponible en:

http://frontex.europa.eu/assets/Publications/Risk Analysis/Annual Risk Analysi s 2017.pdf [Con acceso el 17 de marzo de 2020].

Frontex, 2019. Risk Analysis for 2019 [en línea]. Varsovia: Frontex Risk Analysis Unit, febrero. Localizable en https://frontex.europa.eu/assets/Publications/Risk Analysis/Risk Analysis/Risk Analysis for 2019.pdf [Con acceso el 17 de marzo de 2020].

García Arán, M., 2006. Introducción. En: M. García Arán, ed., Trata de personas y explotación sexual. Granada: Comares, pp. 1-31.

GRETA 2017. Report on Italy, under Rule 7 of the Rules of Procedure for evaluating implementation of the Council of Europe Convention against Trafficking in Human Beings, GRETA(2016)29 [en línea]. 30 de enero. Disponible en: https://rm.coe.int/16806edf35 [Con acceso el 17 de marzo de 2020].

GRETA, 2018. Report concerning the implementation of the Council of Europe Convention Action against Trafficking in human Beings by Italy. Second evaluation round (GRETA(2018)28) [en línea]. 25 de enero. Estrasburgo: GRETA / Comité de las Partes. Disponible en: https://rm.coe.int/greta-2018-28-fgr-ita/168091f627 [Con acceso el 17 de marzo de 2020].

Guardiola Lago, M.J., 2016. La compleja armonización del delito de tráfico ilícito de migrantes (smuggling of migrants): ¿existe un consenso internacional?. En: A.I. Pérez Cepeda, ed., Política Criminal. Ante el reto de la delincuencia transnacional. Valencia: Tirant lo Blanch, pp. 549-591.

International Rescue Committee, NRC y Oxfam, 2017. The reality of the EU-Turkey Statement [en línea]. Nota de prensa, 17 de marzo. Disponible en: https://oi-filesd8-prod.s3.eu-west-2.amazonaws.com/s3fs-public/bn-eu-turkey-statementmigration-170317-en.pdf [Con acceso el 17 de marzo de 2020].

Jordana Santiago, M., 2015. La lucha contra la trata en la UE: Retos de la cooperación judicial penal transfronteriza. Revista CIDOB d'Afers Internacionals, n. .0111 (monográfico: control de fronteras y derechos humanos), pp. 57-77. 
Naciones Unidas, 2019. United Nations Support Mission in Libya - Report of the SecretaryGeneral (S/2019/711) [en línea]. Consejo de Seguridad de Naciones Unidas, 5 de septiembre. Disponible en https://www.refworld.org.es/pdfid/5d8517c54.pdf [Con acceso el 17 de marzo de 2020].

Nyczak, N., 2016. Coyote Ugly: ineffective human smuggling statutes in Central America Call for a new regional treaty. San Diego International Law Journal [en línea], 7(2), pp. 239-293. Disponible en: https://digital.sandiego.edu/ilj/vol17/iss2/3/ [Con acceso el 17 de marzo de 2020].

Oficina de las Naciones Unidas contra la Droga y el Delito, 2007. Manual para la lucha contra la trata de personas (Núm. de venta: S.06.V.11) [en línea]. Viena: UNODC. Disponible en: https://www.unodc.org/pdf/Trafficking toolkit Spanish.pdf [Con acceso el 17 de marzo de 2020].

Oficina de las Naciones Unidas contra la Droga y el Delito, 2011. Contrabando de Migrantes: A um passo do Tráfico de Seres Humanos [en línea]. Noticia. 23 de septiembre. Disponible en: https://www.unodc.org/lpobrazil/es/frontpage/2011/09/23-trafico-ilicito-de-migrantes-a-un-paso-de-la-tratade-personas.html [Con acceso el 17 de marzo de 2020].

Oficina de las Naciones Unidas contra la Droga y el Delito, 2018. Global Report on Trafficking in Persons, Western and Southern Europe [en línea]. Viena: UNODC. Disponible en: https://www.unodc.org/documents/data-andanalysis/glotip/2018/GLOTIP 2018 WESTERN AND SOUTHERN EUROPE.pdf [Con acceso el 17 de marzo de 2020].

Organización Internacional para las Migraciones, 2017. Analysis: flows monitoring surveys. The human trafficking and other exploitative practices prevalence indication survey [en línea]. Junio. Disponible en:

http://migration.iom.int/docs/Analysis_Flow_Monitoring_and_Human_Trafficki ng Surveys in the Mediterranean and Beyond 14 June 2017.pdf [Con acceso el 17 de marzo de 2020].

Organización Internacional para las Migraciones, 2019. Flow monitoring. Libya-migrant report 25 (March-May 2019) [en línea]. Julio. Disponible en: https://migration.iom.int/reports/libya-\%E2\%80\%94-migrant-report-25march\%E2\%80\%94may-2019í [Con acceso el 17 de marzo de 2020].

Organización Internacional para las Migraciones, sin fecha. Missing Migrants Project: Total of Deaths Recorded in the Mediterranean [en línea]. Datos. Disponible en: https://missingmigrants.iom.int/region/mediterranean [Con acceso el 17 de marzo de 2020].

Pérez Cepeda, A., 2004. Globalización, tráfico internacional ilícito de personas y derecho penal. Granada: Comares.

Perry, A., y Agius, C., 2015. A carpet of people in the sea. Newsweek, nº 34, 19 de junio.

Verdú, D., 2017. El barco ultra que quiere frenar la inmigración a través del Mediterráneo. El País [en línea], 20 de julio. Disponible en: https:/elpais.com/internacional/2017/07/19/actualidad/1500481785 096840.html [Con acceso el 17 de marzo de 2020]. 
Villacampa Estiarte, C., 2011. El delito de trata de seres humanos: Una incriminación dictada desde el Derecho internacional. Cizur Menor: Aranzadi.

\section{Normativa}

Italia

Ley de inmigración consolidada (Testo unico sull'immigrazione). Decreto legislativo, testo coordinato, 25/07/1998 n 286. G.U. [en línea], 18/08/1998. Disponible en: http://www.altalex.com/documents/news/2014/04/08/testo-unico-sullimmigrazione-titolo-ii\#titolo2 [Con acceso el 17 de marzo de 2020].

Europa

Convenio del Consejo de Europa sobre la lucha contra la trata de seres humanos, 2005 [en línea]. Disponible en: https://rm.coe.int/16805d41b7 [Con acceso el 17 de marzo de 2020].

Decisión marco 2002/946/JAI del Consejo, de 28 de noviembre de 2002, destinada a reforzar el marco penal para la represión de la ayuda a la entrada, a la circulación y a la estancia irregulares [en línea]. Disponible en: https://eurlex.europa.eu/legal-content/ES/TXT/?uri=celex:32002F0946 [Con acceso el 17 de marzo de 2020].

Directiva 2002/90/CE del Consejo, de 28 de noviembre de 2002, destinada a definir la ayuda a la entrada, a la circulación y a la estancia irregulares. Diario Oficial de las Comunidades Europeas [en línea], L 328/17, de 5 de diciembre de 2002. Disponible en: https://www.boe.es/doue/2002/328/L00017-00018.pdf [Con acceso el 17 de marzo de 2020].

Directiva 2011/36/UE del Parlamento Europeo y del Consejo, de 5 de abril de 2011, relativa a la prevención y lucha contra la trata de seres humanos y a la protección de las víctimas. Diario Oficial de la Unión Europea [en línea], L 101 de 15 de abril de 2011. Disponible en: https://www.boe.es/doue/2011/101/L00001-00011.pdf [Con acceso el 17 de marzo de 2020].

Plan de Acción de la UE contra el Tráfico de Migrantes (2015-2020), Comisión Europea, COM(2015) 285 final, de 27 de mayo de 2015 [en línea]. Disponible en:

http://www.europarl.europa.eu/meetdocs/2014 2019/documents/libe/dv/com co m\%282015\%290285/com com\%282015\%290285 es.pdf [Con acceso el 17 de marzo de 2020].

Internacional

Convención de las Naciones Unidas contra la Delincuencia Organizada Transnacional y sus Protocolos, 2004 [en línea]. Viena: UNODC. Disponible en:

https://www.unodc.org/documents/treaties/UNTOC/Publications/TOC\%20Conve ntion/TOCebook-s.pdf [Con acceso el 17 de marzo de 2020].

Convención sobre el Estatuto de los Refugiados. Ginebra, 28 de julio de 1951. Serie Tratados de Naciones Unidas [en línea], nº. 2545, vol. 189, p. 137. Disponible en: https://www.acnur.org/5b0766944.pdf [Con acceso el 17 de marzo de 2020]. 
Convenio Internacional sobre Búsqueda y Salvamento Marítimos, 1979, enmendado en 2004 mediante Resolución MSC 155 (78) y desarrollado en Res MSC.167(78) de 20 de abril de 2004. Boletín Oficial del Estado [en línea], nº. 43, de 19 de febrero de 2007, págs. 7079-7080. Disponible en:

https://www.boe.es/boe/dias/2007/02/19/pdfs/A07079-07080.pdf [Con acceso el 17 de marzo de 2020].

Protocolo Contra el Tráfico Ilícito de Migrantes por Tierra, Mar y Aire, que Complementa la Convención de las Naciones Unidas Contra la Delincuencia Organizada Transnacional. Serie Tratados de Naciones Unidas [en línea], nº 39574, Vol. 2241. Disponible en:

http://www.oas.org/juridico/spanish/tratados/sp proto cont $\operatorname{tr} \% \mathrm{C} 3 \% \mathrm{~A} 1 \mathrm{fi} 1 \% \mathrm{C} 3$ \%ADci migra tierra mar aire comple conve nu cont delin orga transn.pdf [Con acceso el 17 de marzo de 2020].

Protocolo para prevenir, reprimir y sancionar la trata de persones, especialmente mujeres y niños, que complementa la Convención de las Naciones Unidas contra la Delincuencia Organizada Transnacional. Serie Tratados de Naciones Unidas [en línea], nº. 39574, vol. 2237. Palermo: Naciones Unidas, 15 de noviembre de 2000. Disponible en: https://www.ohchr.org/documents/professionalinterest/protocoltraffickinginpers ons sp.pdf [Con acceso el 17 de marzo de 2020].

Protocolo sobre el Estatuto de los Refugiados. Nueva York, 31 de enero de 1967. Serie Tratados de Naciones Unidas [en línea], nº. 8791, vol. 606, p. 267. Disponible en: https://www.acnur.org/5b076dcd4.pdf [Con acceso el 17 de marzo de 2020].

\section{Dictámenes y jurisprudencia}

Internacional

Chowdury y otros c Grecia, sentencia nํ. 21884/15. Tribunal Europeo de Derechos Humanos, Sección Primera, 30 de marzo de 2017 [en línea]. Disponible en: https://www.mjusticia.gob.es/cs/Satellite/Portal/1292429079733?blobheader=appli cation \%2Fpdf\&blobheadername1=Content-

Disposition\&blobheadername2 $=$ Grupo\&blobheadervalue $1=$ attachment $\% 3 \mathrm{~B}+$ filen ame\%3DSentencia Chowdury y otros v Grecia.pdf\&blobheadervalue2=Docs $\mathrm{T}$ $\underline{\mathrm{EDH}}$ [Con acceso el 17 de marzo de 2020].

Khlaifia y otros c Italia, sentencia no.16483/12. Tribunal Europeo de Derechos Humanos, Gran Sala, 15 de diciembre de 2016.

Osayi Omo-Amenaghawon c. Dinamarca, CCPR/C/114/D/2288/2013. Dictamen del Comité de Derechos Humanos, 23 de julio de 2015.

España

Sentencia del Tribunal Supremo 396/2019. Sala de lo penal, casación, sala 2ª 24 de julio de 2019.

Sentencia del Tribunal Supremo 538/2016. Penal, Procedimiento abreviado, sala 2a․ 17 de junio de 2016. 
Sentencia del Tribunal Supremo 807/2016. Penal- Procedimiento abreviado, sala 2a . 27 de octubre de 2016.

Sentencia del Tribunal Supremo 824/2016, Recurso de casación del 4 de marzo de 2016. Italia

Confirmación de la orden de detención preventiva emitida por el Tribunal de primera instancia de Calabria, ref. 3714/2016 R.G.N.R, 23 de junio de 2016

Decisión del Tribunal de primera instancia de Palermo 3714/2016 R.G.N.R. de 26 de junio de 2016.

Orden de detención preventiva del Tribunal de Palermo, ref. 615/2017 DDA R.G.N.R. de 31 de mayo de 2017. 